Martin K. Obrist

\title{
Flexible bat echolocation: the influence of individual, habitat and conspecifics on sonar signal design
}

Received: 21 February 1994/Accepted after revision: 6 January 1995

\begin{abstract}
Acoustic signals which are used in animal communication must carry a variety of information and are therefore highly flexible. Echolocation has probably evolved from acoustic communication, still serves such functions and could prove as flexible. Measurable variability can indicate flexibility in a behaviour. To quantify variability in bat sonar and relate it to behavioural and environmental factors, I recorded echolocation calls of Euderma maculatum, Eptesicus fuscus, Lasiurus borealis and L. cinereus while the bats hunted in their natural habitat. I analysed 3390 search phase calls emitted by 16 known and 16 unknown individuals foraging in different environmental and behavioural situations. All four species used mainly multiharmonic signals that showed considerable intra- and inter-individual variability in the five signal variables I analysed (call duration, call interval, highest and lowest frequency and frequency with maximum energy) and also in the shape of the sonagram. A nested multivariate analysis of variance identified the influences of individual, hunting site, close conspecifics and of each observation on the frequency with maximum energy in the calls, and on other variables measured. Individual bats differed in multiple comparisons, most often in the main call frequency and least often in call interval. In a discriminant function analysis with resubstitution, $56-76 \%$ of a species' calls were assigned to the correct individual. Distinct individual call patterns were recorded in special situations in all species and the size of foraging areas in forested areas influenced temporal and spectral call structure. Echolocation behaviour was influenced by the presence of conspecifics. When bats were hunting together, call duration decreased and call
\end{abstract}

Martin K. Obrist ${ }^{1}$

Zoologisches Institut der Universität, Luisenstrasse 14, 80333 München, Germany

Present address:

${ }^{1}$ Swiss Federal Institute for Forest, Snow and Landscape

Research, CH-8903 Birmensdorf, Switzerland interval increased in all species, but spectral effects were less pronounced. The role of morphometric differences as the source of individually distinct vocalizations is discussed. I also examined signal adaptations to long range echolocation and the influence of obstacle distance on echolocation call design. My results allow to discuss the problems of echo recognition and jamming avoidance in vespertilionid bats.

Key words Sonar Echolocation - Variability Jamming avoidance $\cdot$ Vespertilionidae

\section{Introduction}

Strong evidence suggests that echolocation has evolved from vocalizations which originally served a communication function (Fenton 1984). To communicate means to transmit varying information. It is therefore not astonishing that communication calls show a high degree of variation and the question arises whether such variability is also detectable in echolocation.

Flexibility in the echolocation calls of bats has been reported since the beginning of research in this area. Griffin et al. (1960) described the task-dependent temporal and spectral changes of echolocation calls and speculated about underlying patterns and the degree of voluntary control involved in the production of such systematically changing vocalizations. Further study of echolocation demonstrated inter-specific differences in echolocation calls (e.g. Ahlén 1981; Fenton and Bell 1981) which allowed acoustic species identification. However, the documentation of intra-specific variation in search phase echolocation calls (Thomas et al. 1987) made identification tentative, at least in some species.

On an individual level, Möhres (1953) supposed that differences in the echolocation signals of Myotis myotis enabled mothers to recognize their young. Möhres (1967) also described differences in echolocation 
frequencies of individual Rhinolophus ferrumequinum which, he suggested, facilitated individual recognition. A dual function of vocalizations for echolocation and communication has been proposed for many bat species (see Fenton 1985 for review). As for many birds and other mammals (e.g. Beer 1970; Cheney and Seyfarth 1980; Sieber 1986) vocal signatures have been documented for several bat species, mainly in the context of social communication calls involved in mother-young recognition (e.g. Myotis lucifugus, Eptesicus fuscus, Gould 1971; Antrozous pallidus, Brown 1976; Myotis myotis, Kolb 1977; Noctilio albiventris, Brown et al. 1983; Tadarida brasiliensis mexicana, Gelfand and McCracken 1986; Nycticeius humeralis, Scherrer and Wilkinson 1993).

Echolocation can be described as communication about the surroundings to oneself (Simmons et al. 1977). Recognition of the echoes of its calls is as vital for a bat in crowded flight situations as is the recognition of signals in communication between individuals. If bats intentionally apply the control they show over their vocalizations in stages of attack (Griffin et al. 1960 ) or in different hunting environments (Zbinden 1989; Rydell 1990; Schumm et al. 1991; Kalko and Schnitzler 1993), they might well use this control to adjust their call design not only to environmental constraints but also to create unique calls. This would help to ensure echo recognition and avoid mutual disturbances that could reduce perceptual performance (jamming). Indications of call separations have been found in the Hipposideridae (Pye 1972), Rhinopoma hardwickei (Habersetzer 1981), Rhinolophus rouxi (Neuweiler et al. 1987), and some vespertilionids (Belwood and Fullard 1984; Schnitzler et al. 1987; Brigham et al. 1989; Zbinden 1989). All these studies document differences in spectral variables, but none monitored the echolocation behavior of known individuals over extended periods in natural hunting situations. Only recently have studies of individual differences in echolocation calls been performed. However, of these, Jones et al. (1991, 1992) report only from indoor recordings and the field recordings of Rydell (1993) cannot elucidate the influence of conspecifics. Neither study can clarify the full flexibility individual bats exhibit in vocalizations emitted during natural foraging.

The purpose of this study was to test the hypothesis that individual free-ranging bats foraging under natural conditions in the field show quantifiable intra- and inter-individual differences in their echolocation calls. I expected that the results would relate to differences in foraging habitat and behavioural situation. Correlation of inter-individual differences with morphometric differences should be examined. Finally, the possibility that vespertilionid bats use their call flexibility to avoid mutual disturbances of their acoustic orientation (jamming avoidance response, JAR) should be tested. Call changes only occurring upon the arrival of a second bat and independent of the relative position of the two bats would support such a hypothesis.

\section{Materials and methods}

Capture and marking of bats

Field recordings were made in the Okanagan Valley $\left(49^{\circ} 18^{\prime} \mathrm{N}\right.$, $119^{\circ} 33^{\prime}$ W), British Columbia, in May and June of 1986 (Eptesicus fuscus and Euderma maculatum) and in Pinery Provincial Park $\left(43^{\circ} 15^{\prime} \mathrm{N}, 81^{\circ} 51^{\prime} \mathrm{W}\right)$, Ontario, in July and August of 1986 (Lasiurus borealis and L. cinereus). To allow repeated recordings of known individuals and for examining within-individual variability, bats were captured with mist nets or harp traps, marked with reflective bands bearing a unique colour combination and released. Four individual bats ( $2 \mathrm{E}$. fuscus, 2 Eu. maculatum) were also outfitted with 0.8 -g radio transmitters (Holohil Systems, R.R. 2 Woodlawn, Ontario, Canada K0A $3 \mathrm{M} 0$ ) so their regular feeding site could be identified. Recordings of E. fuscus were made while bats foraged $5-10 \mathrm{~m}$ above the Okanagan River, near Okanagan Falls, at least $5 \mathrm{~m}$ from the closest shoreline vegetation. Eu. maculatum were recorded as they foraged in wide loops (diameter $>$ $50 \mathrm{~m}$ ) at least $10 \mathrm{~m}$ above an open bunchgrass (Agropyron spp.) meadow between the west shore of Vaseux Lake and a stand of ponderosa pine (Pinus ponderosa) in the Okanagan Valley. L. borealis and $L$. cinereus were recorded as they foraged around four illuminated parking lots surrounded by oak-pine forest ( $Q u e r c u s$ spp., Pinus spp.) at Pinery Provincial Park. L. borealis in particular often veered off towards the lights and attacked conspicuous large moths. I focused on vocalizations emitted in search flight (Griffin et al. 1960 ) when the bats were $>10 \mathrm{~m}$ away from the lights. Recordings made during attacks were not analysed even though I thereby restricted the scope of potential variability. However in these situations dramatically altering calls can be difficult to assign to a behavioural stage; very short buzz calls ( $1 \mathrm{~ms}$ ) came close the temporal resolution of the analysis equipment, and assigning calls to individuals became impossible in simultaneous attacks of two bats on one target.

At each site, the recording position was fixed and at a similar distance from vegetation to minimize artefacts due to intra- or intersite variability. Only two $E u$. maculatum were captured and E. fuscus chewed the reflective tape off their bands within 3 days. I therefore recorded only two known individuals for each of these species and included in my analysis echolocation call sequences from unbanded bats (Table 1), treating them as individuals.

Sound recording and analysis

Echolocation calls were recorded on a Racal Store 4D tape recorder operated at $76 \mathrm{~cm} / \mathrm{s}$ with a QMC \$200 microphone (sensitivity variation of $\pm 5 \mathrm{~dB}$ between $10-100 \mathrm{kHz}$ ). To control for directional sensitivity of the microphone I aimed it by hand at bats passing tangentially at an angle of $\approx 90^{\circ}$, avoiding direct frontal and dorsal recordings. I used headphone control of a parabolic reflector microphone mounted parallel to the actual "data" microphone to point the system accurately at the bat of interest. The signals from this highly directional microphone were recorded on a separate tape track and were later used to unambigously identify signals from individual bats in situations where conspecifics were present (Fig. 1).

A hand-held spotlight was momentarily switched on prior to recording to identify individuals by the colour combination of reflective bands and to observe flight behavior and position relative to the ground and obstacles. During recordings an assistant monitored the recording levels of the QMC S200 and output 

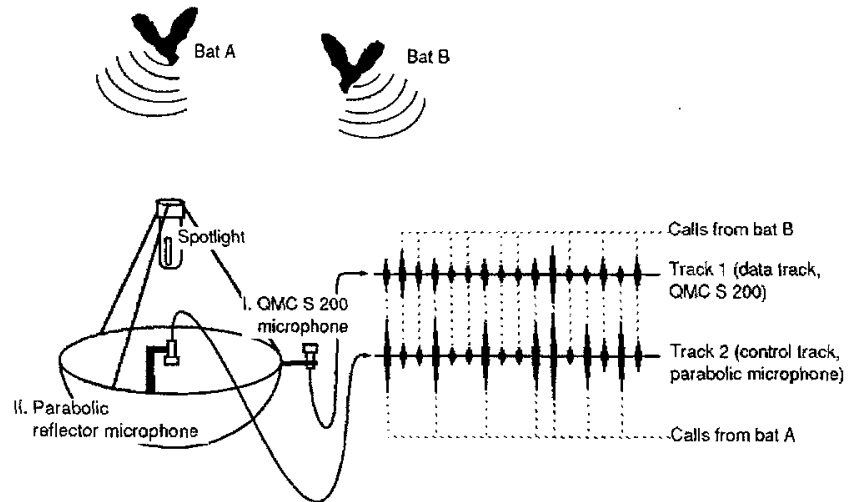

Fig. 1 Recording and call identification. Method of recording and identifying individuals in recordings of several bats. Recordings were made on separate tracks with a normal microphone and a highly directional parabolic reflector microphone. Identification was achieved by aligning the two recorded tracks and marking signals on track 1 that were recorded louder on track 2 as belonging to bat $A$

levels of the tape on a Tektronix 212 oscilloscope. Weakest signals were $\approx 15 \mathrm{~dB}$ less intense than the strongest, recorded when the bats reached closest recording distance. I analysed 1519 vocalizations emitted by individuals with no other bats flying within the detection range of the recording system (approx. 30-50 m for $E$. fuscus and the lasiurines, $150 \mathrm{~m}$ for Eu. maculatum), and 1871 calls emitted when conspecifics were present (Table 1).

I analysed only calls from selected echolocation sequences (succession of calls emitted during one recorded pass; defined as one observation) of good recording quality (high signal-to-noise ratio, Figs. 2 and 3, amplitude display insets; Table 1). The interval between recording sessions (observations) of known individuals varied from 20 seconds (E. fuscus) to 27 days (Eu. maculatum). My analysis was restricted to vocalizations emitted in the context of general scanning for insects (search phase echolocation calls, Griffin et al. 1960) as judged from the observed straight flight behavior and temporal pattern of call emission. Only calls of bats passing at least $5 \mathrm{~m}$ away from solid obstacles in straight flight tangential to the recording position were analysed, to minimize variation due to background influence, Doppler effects or directionality of sound emissions. The recordings were therefore made at roughly $90^{\circ}$ to the flight direction of the vocalizing animals.

Signals were digitized from real-time tape playback with a $250 \mathrm{kHz}$ sampling rate and stored in an 8 kilobyte transient recorder with 8-bit resolution. Triggering occurred from the tape through a prerecorded time code (time code generator/translator, Datum model 9300), that allowed sequential storage in steps of $\geq 1 \mathrm{~ms}$. The signals were attenuated (Integrierte Dämpfungsdekade IDD 1000, Elementa, Nürnberg) or amplified (Philips PM5171 amplifier/ logarithmic converter) before storage in order to use the full dynamic range of the 8-bit memory. Captured signals were then transferred in slowed down mode through a Ubiquitous UA-500 spectrum analyser to a custom-made sonagraph to generate a frequency-over-time display (sonagram) of the echolocation call on a graphics monitor (Hewlett Packard, HP-1304A display) with amplitude coded as screen brightness ( 7 bits dynamic range). A window of 128 consecutive 128-point-spectra was then transferred to a micro computer (Compaq Portable III) for analysis with an adapted ASYST program (ASYST Software Technologies). Using a Grundig TG-1000 frequency generator and a Philips PM5705 pulse generator I calibrated the frequency and time domain of the complete analysis system independently in $5 \mathrm{kHz}$ and $1 \mathrm{~ms}$ steps over the display window of $100 \mathrm{kHz}$ and $32 \mathrm{~ms}$. Thus, frequency and time could be extracted with the software program from the sonagraphic display. The resolution was $0.78 \mathrm{kHz}$ and $0.25 \mathrm{~ms}$; the spectral resolution was $0.39 \mathrm{kHz}$ in $E u$. maculatum where a $50-\mathrm{kHz}$ analysis window was applied.

I measured five call variables: the time interval between successive call beginnings (INT), the call duration (DUR), the highest (HFR) and the lowest frequency (LFR) in the dominant harmonic and the main frequency (peak energy) in the power spectrum (MFR). Temporal spacing of successive trigger events indicated the call interval. The main frequency was automatically found by peak detection in the power spectrum. Call duration, highest and lowest frequencies were calculated by searching from the peak intensity (in the envelope or power spectrum) on both sides for the first number reaching a value below the background noise level plus $6 \mathrm{~dB}$. The noise level was extracted from the first 10 of the 128 transferred spectra which were kept free of vocalizations. Calculations could be corrected if visual control revealed obvious errors (e.g. strong echoes, detectable in the sonagram, lead to expanded durations). Further details of the analysis are given in Obrist (1988).

I compared variables statistically using SAS and SYSTAT statistical software. I used a nested multivariate analysis of variance (MANOVA) model to calculate the variability of the data for every species (model type: parameter $_{(1-5)}=$ constant + site + individual $\{$ site $\}+$ conspecifics $\{$ individual\} + observation $\{$ individual\}; here $x\{y\}$ means $x$ is nested in $y$ ). The coefficient of variation (CV) was calculated to acquire a measure of variability independent of the position of the mean (e.g. comparing highest and lowest frequencies; $\mathrm{CV}$ in percent $=($ standard deviation $/$ mean $) \times 100)$. To find differences between specific individuals or sites I compared call variable means between individuals and between different recording sites with the Ryan-Einot-Gabriel-Welsch multiple range test recommended by Day and Quinn (1989) for such data. Individuals were also compared using a discriminant function analysis with reclassification (SAS: PROC DISCRIM settings SIMPLE POOL $=$ TEST). The within covariance matrices were used in the discriminant function and the resubstitution used the quadratic discriminant function. Relatedness of individual's calls were illustrated with multidimensional scaling (SYSTAT: MDS of Euclidian distance of transposed means). If not otherwise stated a significance level of $P=0.05$ applies.
Table 1 Number of calls of four bat species: sample size per species and behavioural situation Column $A$ number of echolocation sequences (observations) analysed, $B$ : number of calls analysed; $C$ : number of banded bats recorded, $D$ : number of unbanded bats recorded

\begin{tabular}{|c|c|c|c|c|c|c|c|c|c|c|}
\hline \multirow{3}{*}{ Sample size per species } & \multicolumn{8}{|c|}{ Flying } & & \\
\hline & \multicolumn{4}{|c|}{ Alone } & \multicolumn{4}{|c|}{ With conspecifies } & \multicolumn{2}{|c|}{ Total } \\
\hline & A & B & $\mathrm{C}$ & $\mathrm{D}$ & A & B & $\mathrm{C}$ & $\mathrm{D}$ & A & B \\
\hline Eptesicus fuscus & 14 & 287 & 2 & 7 & 30 & 548 & 2 & 28 & 44 & 835 \\
\hline Euderma maculatum & 21 & 701 & 2 & 9 & 23 & 683 & 2 & 21 & 44 & 1384 \\
\hline Lasiurus borealis & 13 & 324 & 6 & 0 & 15 & 315 & 6 & 9 & 28 & 639 \\
\hline L. cinereus & 11 & 207 & 6 & 0 & 15 & 325 & 6 & 9 & 26 & 532 \\
\hline Total & 59 & 1519 & 16 & 16 & 83 & 1871 & 16 & 67 & 142 & 3390 \\
\hline
\end{tabular}




\section{Results}

Variation in echolocation calls

The design (Figs. 2 and 3) and general characteristics (Table 2) of the echolocation calls of the four species
I recorded were similar to previously published data (e.g. Griffin 1958; Fenton and Bell 1981; Leonard and Fenton 1983; Barclay 1986). The CV of call variables ranged from $6 \%$ to $39 \%$ but increased when conspecifics were present (see below). Temporal variables generally showed higher CV's than spectral variables,
Fig. 2 Call variability. Amplitude display and sonagrams of echolocation calls of A-E Euderma maculatum and E-M Eptesicus fuscus, documenting variability of sonagram forms. The double note calls of Eu. maculatum (B, E) most likely contain echoes. "Jagged" sonagram shapes (manually outlined in white for emphasis; $\mathbf{J}, \mathbf{K})$ and sigmoidal sweep starts or ends (encircled; I, L) are marked.

\section{Euderma maculatum}
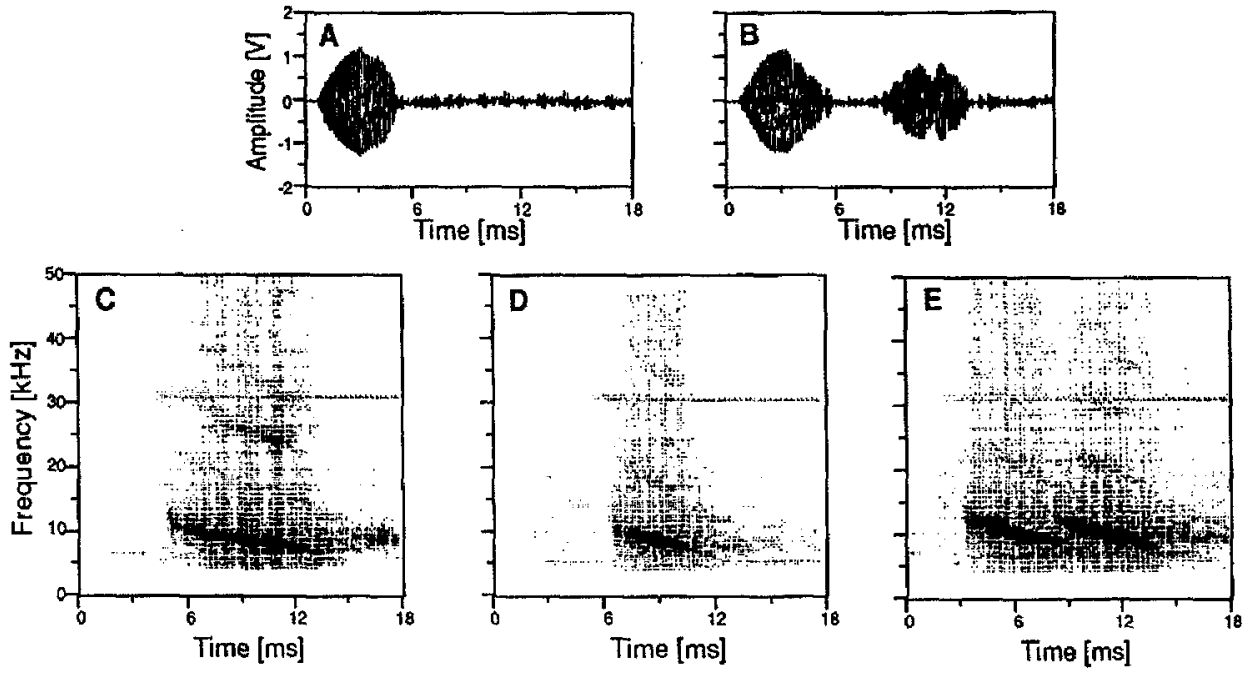

\section{Eptesicus fuscus}
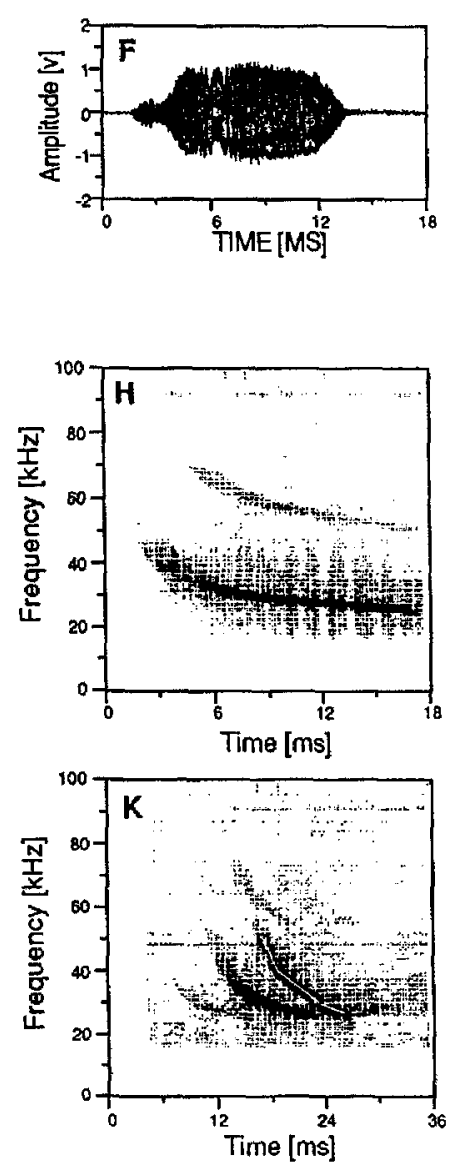
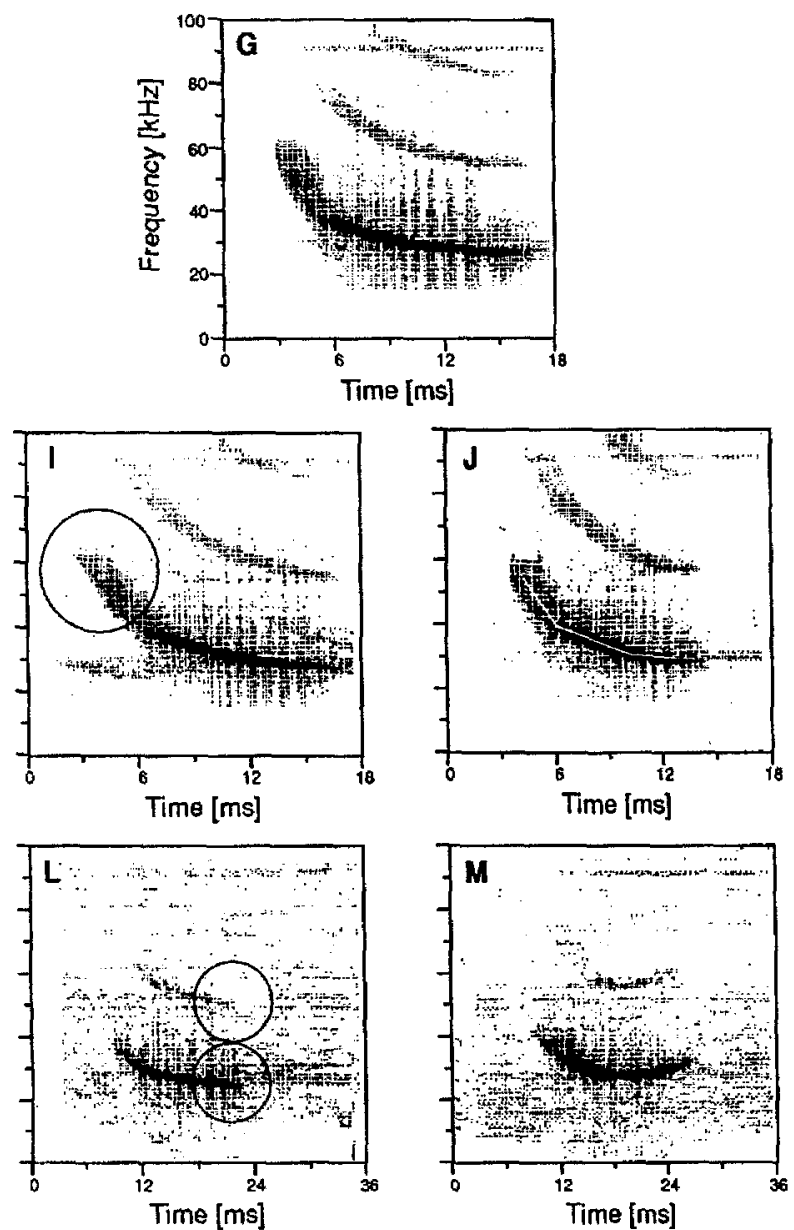
Fig. 3 Call variability.

Amplitude display and sonagrams of echolocation calls of A-F Lasiurus borealis and $\mathrm{G}-\mathrm{L} L$. cinereus, documenting variability of sonagram forms. "Jagged" sonagram shapes (manually outlined in white for emphasis; F, L) are marked

\section{Lasiurus borealis}
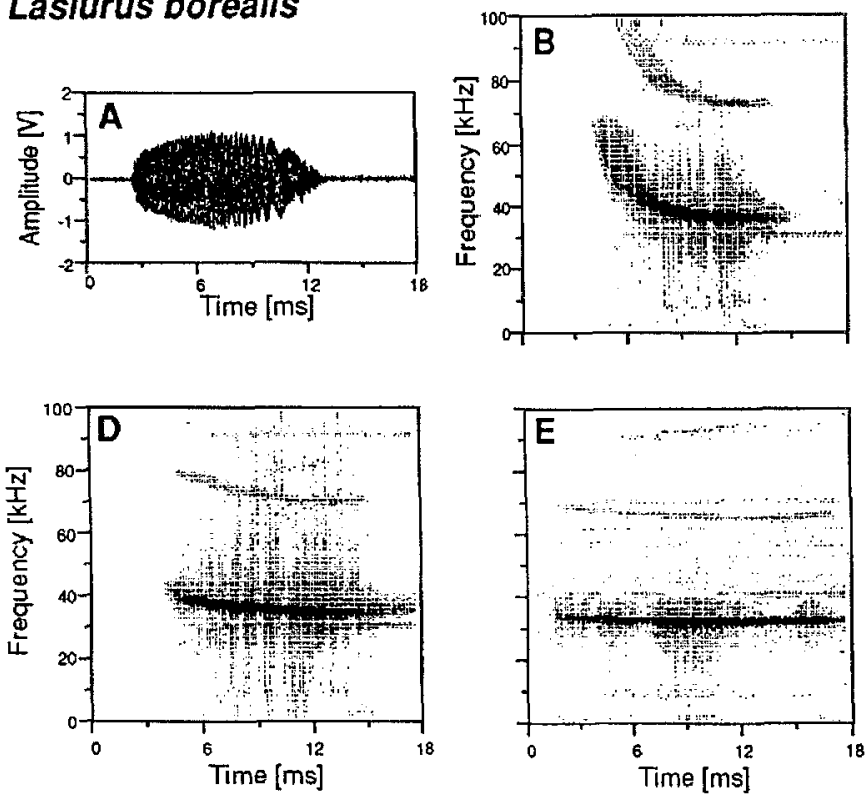

Lasiurus cinereus
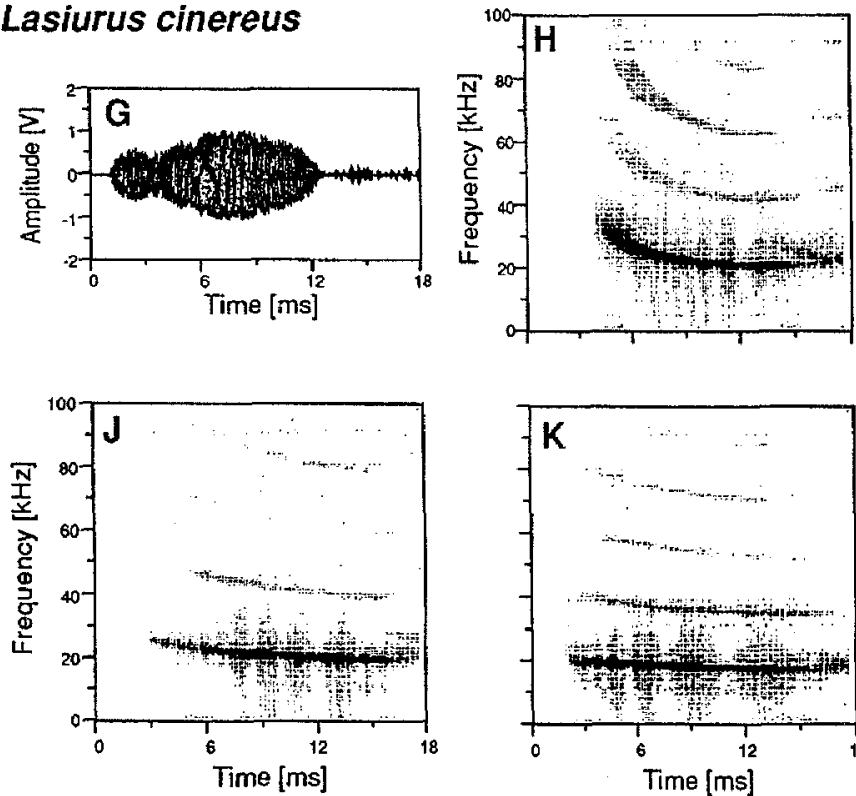

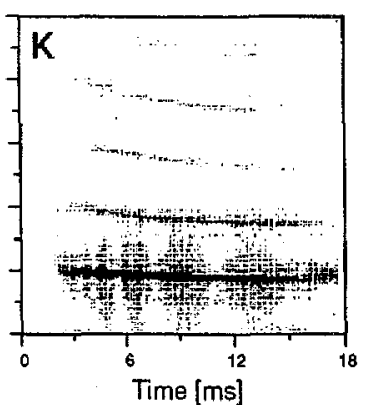

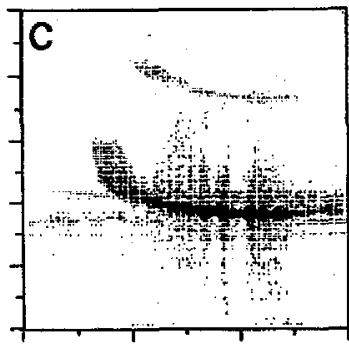
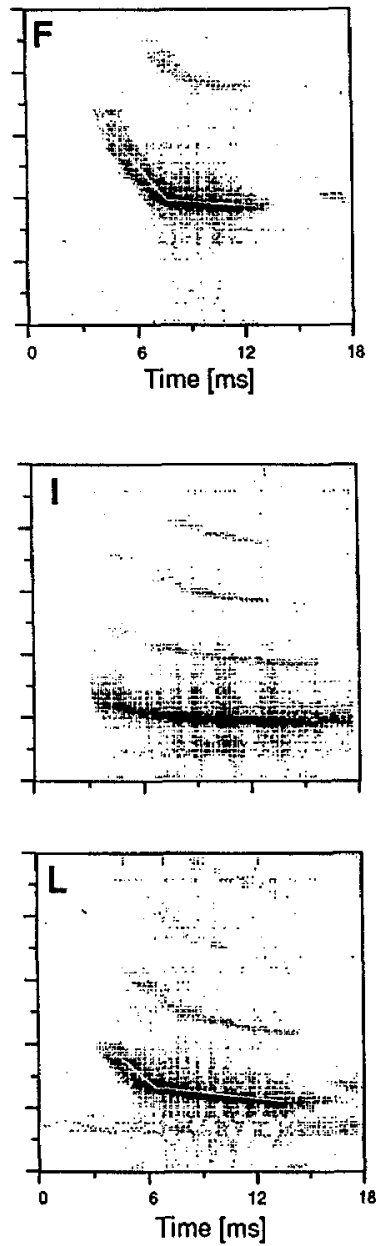

Table 2 Call variables: statistics of analysed calls, separated by species and behavioural situation (DUR call duration, INT call interval between the beginning of successive calls, $M F R$ frequency

of main energy in call, $H F R$ highest frequency in fundamental of call, $L F R$ lowest frequency in fundamental, $M N$ mean) For sample sizes see Table 1 , column B

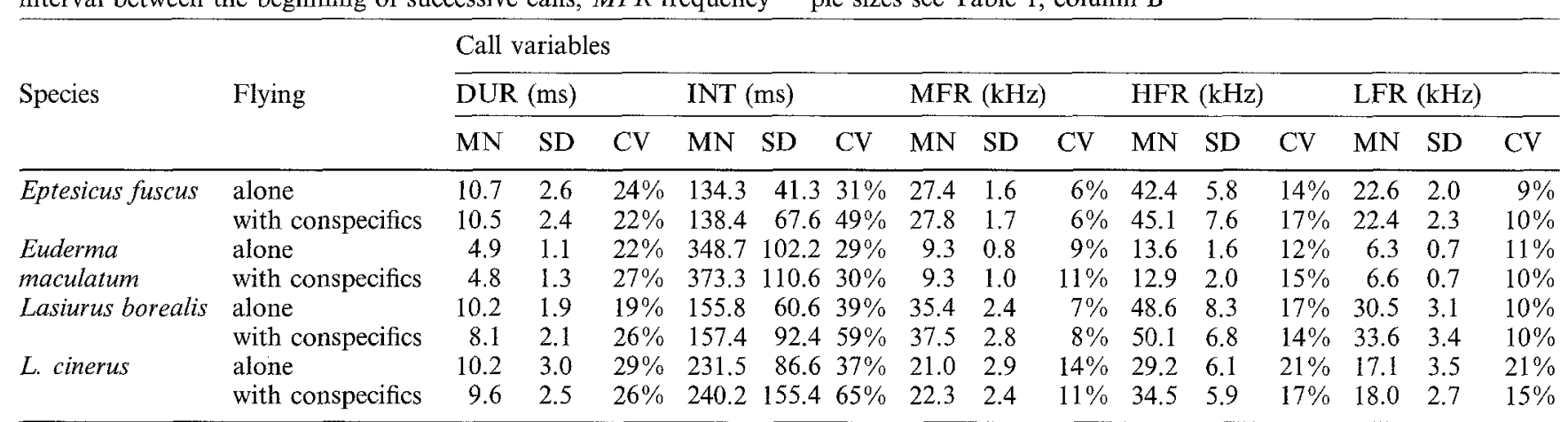


with call interval always showing the highest $\mathrm{CV}$ and the main call frequency (MFR) the lowest.

The variability of sonagram forms found in the four species are outlined in Figs. 2 and 3. For representative calls a time amplitude display is also included (Fig. 2A, B, F; Fig. 3A, G). The figures are meant to illustrate the range of observed calls and also focus on special call designs. The echolocation calls of Eu. maculatum showed a second harmonic (fundamental $=$ first harmonic) 20-30 dB weaker than the fundamental (Fig. 2D, E), but some signals contained up to four harmonics (Fig. 2C). In some recordings I found "double note calls", as described by Leonard and Fenton (1983). The second call was always fainter than the first, the time interval varied between 6 and $13 \mathrm{~ms}$ and the sonagrams where very similar altogether, indicating an echo from the ground (Fig. 2B, E).

Search phase echolocation calls of $E$. fuscus contained a second harmonic about $20 \mathrm{~dB}$ less intense than the first and occasionally a third harmonic (Fig. 2G-M). Echolocation calls of this species had the largest bandwidth relative to the other three species. However, signals up to $19.7 \mathrm{~ms}$ long with an overall bandwidth of only $15 \mathrm{kHz}$ and less than $5 \mathrm{kHz}$ in the second two thirds of the call duration (Fig. 2H) occurred in E. fuscus. Individual differences in sonagram shape are evident. For example one individual consistently used signals with a short linear frequency modulated (FM) sweep in the middle part of the vocalization (Fig. 2J). This jagged sonagram shape was often the only difference between calls of this and a second bat flying close by (Fig. 2K). Sonagrams of other bats' calls occasionally started or ended with sigmoidal sweeps (Fig. 2I, L; circled). Finally, I recorded one call that rose in frequency at the end (Fig. 2M).

L. borealis often produced narrow-band signals $(<5 \mathrm{kHz}$ bandwidth; Fig. 3E). These vocalizations always had a second harmonic $15-25 \mathrm{~dB}$ weaker than the first. Frequency sweeps showed all intermediate forms of a prominent but variably steep beginning and a shallow FM end (Fig. 3B-D). Individuals could drastically change call designs (mostly in the frequency domain) from one call to the next without an obvious reason (such as an initiation of a capture or a obstacle avoidance maneuver). As in E. fuscus, some L. borealis consistently emitted calls of unique sonagram shape in repeated observations (Fig. 3F).

Although the duration and sonagram shapes of calls were similar for the two lasiurine species, vocalizations of $L$. cinereus occupied a $14 \mathrm{kHz}$ lower spectral band. This species' signals were composed of up to four harmonics and the second harmonic was 20-30 dB weaker than the most intense fundamental. Sonagrams again exhibited differently prominént steep FM parts (Fig. 3H-J), but smooth sonagram curving, as seen in E. fuscus (Fig. 2G), was rare. L. cinereus made extensive use of narrow-band calls (fundamental bandwidth
$<7 \mathrm{kHz}$; Fig. 3K). I also witnessed consistent interindividual differences in sonagram characteristics for L. cinereus. (Fig. 3L).

I performed a nested multivariate analysis of variance (MANOVA) to quantify any variability in the recorded echolocation calls (Table 3 ). For most variables, individual differences explain most of the observed variability in the data, followed by observation, behavioural situation and site effects. The highest call frequency is most often significantly affected by one of the sources analysed, followed by the lowest and the main frequency, the duration and finally the interval. As E. fuscus and Eu. maculatum were recorded in one place, I could not calculate a site effect for them. In both species a large variance component in all variables except the call interval can be attributed to individual differences. Individual effect explains less of the total variability in the lasiurines but is most obvious in call duration and, in $L$. borealis, in the lowest call frequency. $L$. borealis and $L$. cinereus showed substantial variability attributable to the presence of conspecifics. These two species regularly hunted close to other bats, while Eu. maculatum only occasionally met conspecifics. In all four species, a considerable component of the variance is related to differences between observations (recording sequences).

\section{Individual differences}

Using a multidimensional scaling (MDS), the difference between species and individuals becomes obvious. I performed MDS in two dimensions (Fig. 4) and the major variation is displayed on the first dimension. Dimension 1 is dominated by spectral influences, with the four species separated along the frequency axis of their calls (high frequencies to the right). Within-species differences are less and some individuals appear very similar in this graph.

After the MANOVA a post hoc multiple comparisons of means was performed to pinpoint the individuals differing from others. Individuals flying alone differed more often in spectral than temporal variables (Fig. 5). On average, more than $60 \%$ of the individual comparisons differed in the main call frequency, $23 \%$ differed in call interval. However, the four species' individual call signatures were based on different variables. In Eu. maculatum, $50 \%$ of all individual pairs differed in their call interval, this was true in $7 \%$ of the $L$. borealis pairs. Similarly, $72 \%$ of all possible $E$. fuscus pairs differed in their call duration, while in Eu. maculatum only $29 \%$ did so.

To further distinguish between individuals and to calculate theoretical potential of calls to be correctly assigned to the sender, I performed a discriminant function analysis with resubstitution (Table 4). For all species the majority of calls emitted when hunting alone were properly assigned to an individual bat. Correct 
Table 3 Results of MANOVA. For every species and call variable the percentage of the total variability explained by a specific source is indicated. (DUR call duration, INT call interval between the beginning of successive calls, $M F R$ frequency of main energy in call, $H F R$ highest frequency in fundamental of call, $L F R$ lowest frequency in fundamental)

\begin{tabular}{|c|c|c|c|c|c|c|c|c|c|c|c|c|}
\hline \multirow{3}{*}{ Species } & \multirow{3}{*}{ Variance source } & \multicolumn{11}{|c|}{ Call variables } \\
\hline & & \multicolumn{2}{|l|}{ DUR } & \multicolumn{2}{|l|}{ INT } & \multicolumn{2}{|l|}{ MFR. } & \multicolumn{2}{|l|}{ HFR } & \multicolumn{2}{|l|}{ LFR } & \multirow[t]{2}{*}{ AVG } \\
\hline & & & & & & $\begin{array}{l}\text { Percen } \\
\text { Total }\end{array}$ & $\begin{array}{l}f \text { tot } \\
100.0\end{array}$ & & & & & \\
\hline Eptesicus fuscus & $\begin{array}{l}\text { Individual } \\
\text { Conspecifics } \\
\text { Observation } \\
\text { Error }\end{array}$ & $\begin{array}{r}39.6 \\
3.8 \\
0.9 \\
55.7\end{array}$ & $\begin{array}{l}* * \\
* * \\
-\end{array}$ & $\begin{array}{r}11.5 \\
0.9 \\
0.3 \\
87.3\end{array}$ & $\begin{array}{l}* * \\
- \\
-\end{array}$ & $\begin{array}{r}66.1 \\
0.6 \\
2.9 \\
30.5\end{array}$ & $\begin{array}{l}* * \\
- \\
* *\end{array}$ & $\begin{array}{r}55.6 \\
1.5 \\
3.4 \\
39.5\end{array}$ & $\begin{array}{l}* * \\
* * \\
* *\end{array}$ & $\begin{array}{r}41.3 \\
3.4 \\
1.5 \\
53.7\end{array}$ & $\begin{array}{l}* * \\
* * \\
* *\end{array}$ & $\begin{array}{r}42.8 \\
2.1 \\
1.8 \\
53.3\end{array}$ \\
\hline Euderma maculatum & $\begin{array}{l}\text { Individual } \\
\text { Conspecifics } \\
\text { Observation } \\
\text { Error }\end{array}$ & $\begin{array}{r}35.5 \\
1.9 \\
12.7 \\
49.9\end{array}$ & $\begin{array}{l}* * \\
* * \\
* *\end{array}$ & $\begin{array}{r}19.0 \\
1.3 \\
3.6 \\
76.1\end{array}$ & $\begin{array}{l}* * \\
* * \\
* *\end{array}$ & $\begin{array}{r}31.5 \\
0.8 \\
2.9 \\
64.9\end{array}$ & $\begin{array}{l}* * \\
* * \\
* *\end{array}$ & $\begin{array}{r}55.9 \\
0.8 \\
7.7 \\
35.6\end{array}$ & $\begin{array}{l}* * \\
* * \\
* *\end{array}$ & $\begin{array}{r}25.1 \\
1.1 \\
6.5 \\
67.4\end{array}$ & $\begin{array}{l}* * \\
* * \\
* *\end{array}$ & $\begin{array}{r}33.4 \\
1.2 \\
6.7 \\
58.8\end{array}$ \\
\hline Lasiurus borealis & $\begin{array}{l}\text { Site } \\
\text { Individual } \\
\text { Conspecifics } \\
\text { Observation } \\
\text { Error }\end{array}$ & $\begin{array}{r}0.6 \\
18.6 \\
11.8 \\
6.6 \\
62.5\end{array}$ & $\begin{array}{l}- \\
* * \\
* * \\
* *\end{array}$ & $\begin{array}{r}3.4 \\
3.9 \\
4.4 \\
2.4 \\
85.9\end{array}$ & $\begin{array}{l}* * \\
* \\
* * \\
-\end{array}$ & $\begin{array}{r}2.1 \\
13.4 \\
7.6 \\
6.6 \\
70.3\end{array}$ & $\begin{array}{l}* * \\
* * \\
* * \\
* *\end{array}$ & $\begin{array}{r}1.8 \\
4.1 \\
13.0 \\
9.0 \\
72.2\end{array}$ & $\begin{array}{l}* * \\
* * \\
* * \\
* *\end{array}$ & $\begin{array}{r}1.3 \\
18.4 \\
5.9 \\
4.2 \\
70.2\end{array}$ & $\begin{array}{l}* \\
* * \\
* * \\
* *\end{array}$ & $\begin{array}{r}1.8 \\
11.7 \\
8.5 \\
5.8 \\
72.2\end{array}$ \\
\hline L. cinereus & $\begin{array}{l}\text { Site } \\
\text { Individual } \\
\text { Conspecifics } \\
\text { Observation } \\
\text { Error }\end{array}$ & $\begin{array}{r}0.5 \\
13.4 \\
2.1 \\
2.7 \\
81.3\end{array}$ & $\begin{array}{l}- \\
* * \\
- \\
*\end{array}$ & $\begin{array}{r}0.5 \\
5.6 \\
1.0 \\
0.7 \\
92.1\end{array}$ & $\begin{array}{l}- \\
* \\
- \\
-\end{array}$ & $\begin{array}{r}4.1 \\
8.7 \\
9.5 \\
7.3 \\
70.3\end{array}$ & $\begin{array}{l}* * \\
* * \\
* * \\
* *\end{array}$ & $\begin{array}{r}6.0 \\
9.0 \\
18.1 \\
4.7 \\
62.1\end{array}$ & $\begin{array}{l}* * \\
* * \\
* * \\
* *\end{array}$ & $\begin{array}{r}3.2 \\
11.8 \\
4.9 \\
11.1 \\
69.0\end{array}$ & $\begin{array}{l}* * \\
* * \\
* * \\
* *\end{array}$ & $\begin{array}{r}2.9 \\
9.7 \\
7.1 \\
5.3 \\
75.0\end{array}$ \\
\hline
\end{tabular}

${ }^{*} P \leq 0.01, * * P \leq 0.001,-P>0.01$

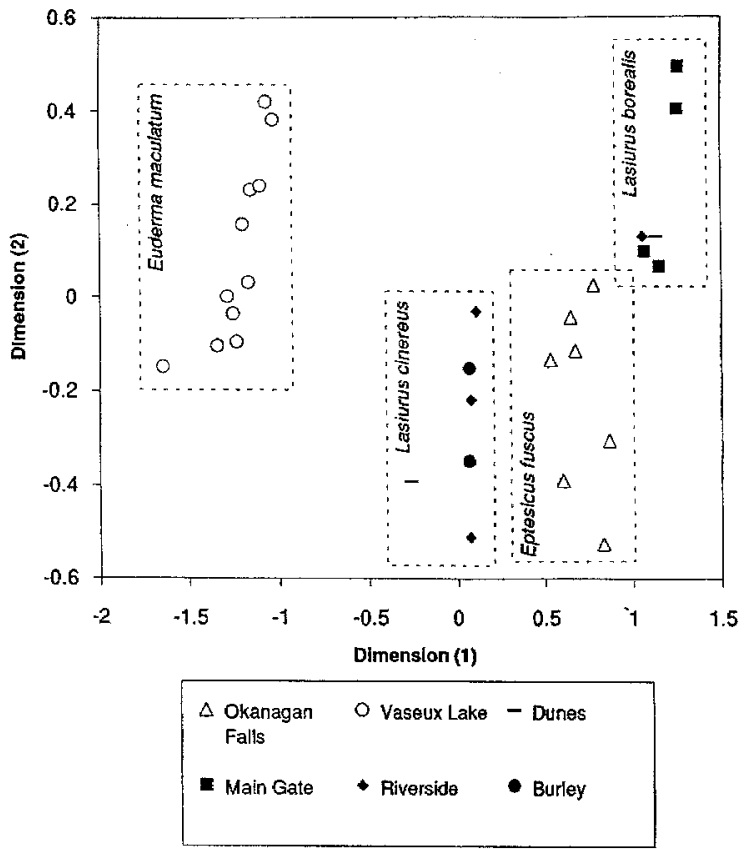

Fig. 4 Multidimensional scaling in two dimensions. Species are grouped by dotted frames, individuals are represented by a data point and recording sites are identified by symbols (sites are described in Methods). Dimension 1 shows the major variation. The two dimensions were calculated with mean values of all five call variables

scores varied between 56\% (L. borealis) and 76\% (E. fuscus; Table 4A). A correlation between a call variable and forearm length could only be established in

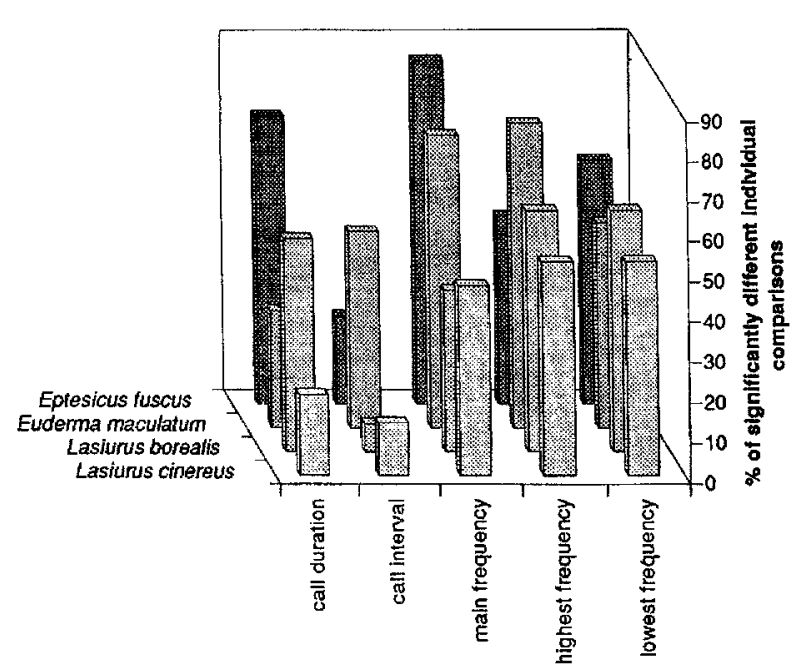

Fig. 5 Multiple comparisons of individual means. Summarized results of multiple mean comparison tests (Ryan-Einot-GabrielWelsch multiple range test). Percentage of individual comparisons which were significantly different are given, separated by species and call variables

L. borealis where forearm length was positively correlated with the lowest call frequency and negatively with call duration.

\section{Distinct call patterns}

The echolocation signals recorded from the two known Eu. maculatum (1 female, 1 male) differed significantly 
Table 4 Discriminant function analysis. A The analysis was performed with calls of all individuals recorded alone per species. B In a second analysis resubstitution was compared in pairs of bats recorded when flying with conspecifics with pairs of single flying bats combined artificially. This comparison of "real" and "virtual" pairs was performed to test whether call variable changes induced by the presence of conspecifics increased the discernability of calls. Number of individuals/pairs, percentage of correct assignment and probability of a correct random assignement are given $(50 \%$ in case of two bats)

\begin{tabular}{lllll}
\hline Species & $\begin{array}{l}\text { Number of } \\
\text { individuals/ } \\
\text { pairs }\end{array}$ & $\begin{array}{l}\text { Correct } \\
\text { resubstitution } \\
\text { score (\%) }\end{array}$ & $\begin{array}{l}\text { Prior probability } \\
(\%)\end{array}$ \\
\hline flying alone & & & \\
A $\quad$ & 9 & 75.9 & 11.1 \\
$\quad$ Eptesicus fuscus & 11 & 60.9 & 9.1 \\
$\quad$ Euderma maculatum & 6 & 55.9 & 16.7 \\
Laisurus borealis & 6 & 65.3 & 16.7 \\
L. cinereus & 32 & 64.5 & 13.4 \\
\hline
\end{tabular}

flying with conspecifics, within REAL pair (same species)

$\begin{array}{lll}\text { Average of all species } \quad 46 & 89.0 & 50.0\end{array}$

B

flying alone, within VIRTUAL pair (same species)

Average of all species $\quad 45 \quad 91.2$

50.0 in some variables. The male called at lower frequencies in significantly longer intervals $(437 \mathrm{~ms}$; female $352 \mathrm{~ms}$ ). Both individuals were recorded at the same location foraging in wide ellipses approximately $10 \mathrm{~m}$ above ground.

I recorded two E. fuscus which used long calls (> $10 \mathrm{~ms}$ ) of average bandwidth $(19.8 \mathrm{kHz})$ alternating with up to $20 \mathrm{~dB}$ fainter calls that were $1-2 \mathrm{~ms}$ shorter with a bandwidth of only $10 \mathrm{kHz}$. The main frequency of all alternating calls was identical and the pattern was only seen in sequences immediately after the final stage of an insect pursuit, a feeding buzz (Griffin et al. 1960).

$L$. borealis and $L$. cinereus foraging $>10 \mathrm{~m}$ from ground or vegetation used comparable patterns of alternating calls ("plip-plop" calls) with the interpulse intervals showing a bimodal distribution with peaks around $110 \mathrm{~ms}$ and $220 \mathrm{~ms}$ in L. borealis and around $200 \mathrm{~ms}$ and $250 \mathrm{~ms}$ in L. cinereus. Calls of high intensity, long duration and average spectral composition alternated with much fainter calls $(\approx-20 \mathrm{~dB})$ of shorter duration $(-1 \mathrm{~ms}$ to $-2 \mathrm{~ms}$ ), higher main frequency $(+2 \mathrm{kHz}$ to $+5 \mathrm{kHz})$ and increased bandwidth. The faint (F) and loud (L) calls alternated in a F-L-F or F-L-L-F fashion.
The influence of recording sites

I recorded the lasiurine bats at sites of different size and shape but surrounded by vegetation of the same type and structure. The four observation sites were 20 $\times 55 \mathrm{~m}$ (Main Gate), $44 \times 135 \mathrm{~m}$ (Dunes), $38 \times 165 \mathrm{~m}$ (Burley) and $50 \times 95 \mathrm{~m}$ (Riverside) in size and were $1.5-2 \mathrm{~km}$ apart. The closest solid obstacles were a maximum of $10 \mathrm{~m}$ (Main Gate), $22 \mathrm{~m}$ (Dunes), $19 \mathrm{~m}$ (Burley), and $25 \mathrm{~m}$ (Riverside) away from the recorded bats. Relative to Riverside, Burley and Dunes, the Main Gate site was obviously smaller and not frequented by L. cinereus. Multiple comparison of means of call variables elucidated site specific differences (Table 5). Hunting at Main Gate, $L$. borealis used significantly shorter calls with higher repetition rates and call frequencies than at larger sites. $L$. cinereus calls were statistically identical in temporal variables at Dunes, Burley and Riverside, but significantly lower in all frequency variables at Dunes.

\section{The effect of conspecifics on echolocation calls}

A considerable amount of variability in the recorded calls is due to the influence of conspecifics (except $E u$. maculatum; Table 3). All four species decrease call duration but increase the interval between successive calls when conspecifics fly close by (Table 2). The effect on

call, $H F R$ highest frequency in fundamental of call, $L F R$ lowest frequency in fundamental.) Sites with identical letters do not differ

significantly in a given variable and species
Table 5 Multiple mean comparison of echolocation calls emitted at different sites ( $D U R$ call duration, $I N T$ call interval between the beginning of successive calls, $M F R$ frequency of main energy in

\begin{tabular}{|c|c|c|c|c|c|c|c|}
\hline & \multirow[b]{2}{*}{ site } & \multicolumn{5}{|c|}{ Call variable means } & \multirow{2}{*}{$\frac{\mathrm{n}}{\text { (calls) }}$} \\
\hline & & DUR (ms) & INT (ms) & $\operatorname{MFR}(\mathrm{kHz})$ & HFR (kHz) & LFR (kHz) & \\
\hline Lasiurus borealis & $\begin{array}{l}\text { Main Gate } \\
\text { Riverside } \\
\text { Dunes } \\
\text { Riverside }\end{array}$ & $\begin{array}{r}9.9 \mathrm{a} \\
10.7 \mathrm{~b} \\
10.8 \mathrm{~b} \\
10.2 \mathrm{a}\end{array}$ & $\begin{array}{l}148.4 \mathrm{a} \\
181.6 \mathrm{~b} \\
167.5 \mathrm{ab} \\
221.4 \mathrm{a}\end{array}$ & $\begin{array}{l}35.7 \mathrm{a} \\
34.8 \mathrm{a} \\
35.0 \mathrm{a} \\
21.1 \mathrm{a}\end{array}$ & $\begin{array}{l}49.3 \mathrm{a} \\
44.6 \mathrm{~b} \\
48.2 \mathrm{a} \\
29.9 \mathrm{a}\end{array}$ & $\begin{array}{l}30.9 \mathrm{a} \\
30.1 \mathrm{ab} \\
29.5 \mathrm{~b} \\
16.9 \mathrm{a}\end{array}$ & $\begin{array}{r}218 \\
28 \\
78 \\
131\end{array}$ \\
\hline L. Cinereus & $\begin{array}{l}\text { Dunes } \\
\text { Burley }\end{array}$ & $\begin{array}{l}10.5 \mathrm{a} \\
10.2 \mathrm{a}\end{array}$ & $\begin{array}{l}265.6 \mathrm{a} \\
243.6 \mathrm{a}\end{array}$ & $\begin{array}{l}17.8 \mathrm{~b} \\
21.6 \mathrm{a}\end{array}$ & $\begin{array}{l}21.7 b \\
29.8 a\end{array}$ & $\begin{array}{l}14.5 \mathrm{~b} \\
18.3 \mathrm{a}\end{array}$ & $\begin{array}{l}18 \\
58\end{array}$ \\
\hline
\end{tabular}




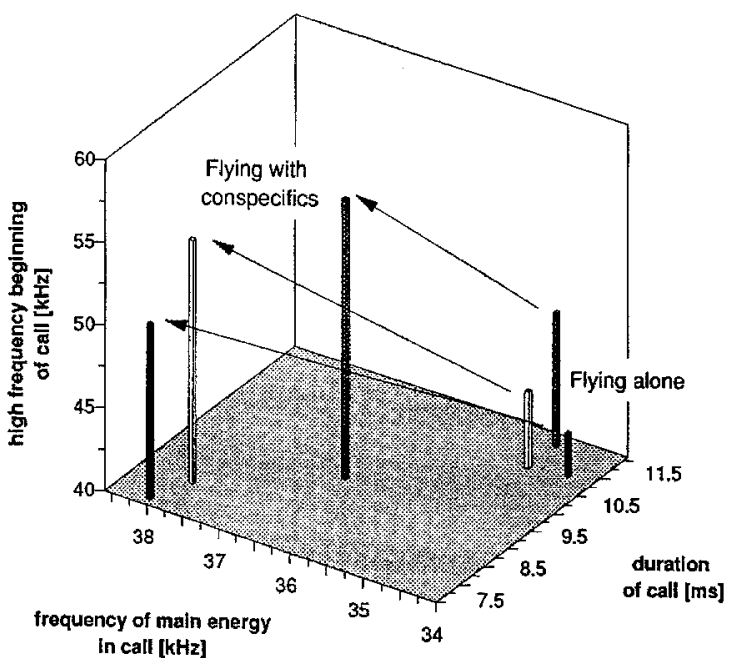

Fig. 6 Call variable shifts. Change of three call variables of three L. borealis in response to the presence of conspecifics. Arrows point toward the values measured when conspecifics were hunting in the vicinity

the spectral composition of the calls is less clear. Eu. maculatum lowers the bandwidth of calls by about $1 \mathrm{kHz}$. E. fuscus increases the bandwidth by rising the high frequency beginning and lowering the low frequency end of their vocalizations. The lasiurines shift the main frequency of their calls upwards $(2.0 \mathrm{kHz}$ $L$. borealis; $1.4 \mathrm{kHz} L$. cinereus). While $L$. cinereus at the same time increases the total bandwidth by $4.4 \mathrm{kHz}$, $L$. borealis decreases this value by $1.7 \mathrm{kHz}$.

To illustrate the call change induced by the presence of other bats, means of call variables of three individual $L$. borealis were plotted as a function of call duration, frequency of main energy and highest frequency (Fig. 6). All three bats behave identically when other bats are present, emitting calls of decreased duration but higher frequency.

To determine whether the call changes induced by the presence of conspecifics, actually increased theoretical recognition of calls, I performed a discriminant function analysis for each individual pair of bats recorded together. On average $89 \%$ of all calls were properly assigned (50\% prior probability). However, combining call sequences of two bats recorded hunting alone, creating "virtual" pairs of bats, produced a slight increase in resubstitution scores (Table 4B).

\section{Discussion}

\section{Methodological considerations}

Several factors affect the quality of outdoor recordings of echolocation calls of free flying bats, including the directionality of the bat's sound emission, the recording characteristic of the microphone, the recording dis- tance and wind, temperature and humidity related transfer functions of acoustic signals (Lawrence and Simmons 1982), as well as the recording equipment. Precautions were taken to minimize these effects. The standardized method of recording minimized directional effects of the microphones and also lessened differential Doppler effects due to flight speed differences. Observed differences in individual flight speeds of up to $5 \mathrm{~m} / \mathrm{s}$ (hand-timed in L. borealis) could account for $0.5-\mathrm{kHz}$ difference in recorded frequencies (emitted at $35 \mathrm{kHz}$ ). The bats were visible during recording, allowing me to assess their approximate height and general flight behavior.

In the analysis I included echolocation calls of unbanded bats in Eu. maculatum and E. fuscus. This seems justified as different individual Eu. maculatum foraged at different times during the night at the same site, slowly moving south during foraging, making place for a next individual to take up its position. In $E$. fuscus I could observe the bats at dusk much further away than I could record them and only restarted recording after sufficient reapproach of an individual I had visually tracked, therefore allowing for a repeated recording of an unbanded animal. The number of bats foraging at Okanagan Falls (hundreds over all, fewer when I recorded) further decreased the chance of an unwanted repeated recording.

In Eu. maculatum, a marginal variance component was related to the behavioural situation (conspecifics; Table 3) perhaps due to the selection of echolocation calls examined. Eu. maculatum reacts vigorously to close conspecifics or playbacks of their calls. It increases pulse repetition rate and starts chasing conspecifics or attacks the playback speaker (Leonard and Fenton 1983). Such close encounters were recorded during this study but not included in the analysis, as the calls differed from "normal" search phase calls.

\section{Sources of variation}

What caused the variation I found in all recordings? Inability of the system to accurately reproduce vocalizations is not an appropriate explanation because some individuals consistently used the same call design over a recorded sequence of several echolocation calls. One possible source of variability is illustrated by the top and bottom frequencies in L. cinereus signals. $L$. cinereus calls sweep through different frequency bands in different regions, ranging from $39.0 \mathrm{kHz}$ as top frequency in Arizona (Fenton and Bell 1981) to $16.9 \mathrm{kHz}$ as the bottom frequency in Manitoba (Barclay 1986). This suggests geographical variation, perhaps reflecting morphometric characteristics which might differ between populations.

Morphometric differences might explain shorter calls and lower frequencies in the male Eu. maculatum I recorded. Similar spectral disparities in the $\mathrm{CF}$ 
frequencies of male and female rhinolophids have been found (Rhinolophus rouxi, Neuweiler et al. 1987; $R$. hipposideros, Jones et al. 1992), but my small sample size prohibits a test of this interpretation. Call structures differing between individuals recorded when flying alone, out of earshot of conspecifics, are probably due to small morphometric differences in the vocal tracts. Such morphometric differences produce individual frequency composition in the orientation clicks of oilbirds, which can improve signal recognition in crowded cave situations (Suthers and Hector 1988). As in other species (R. hipposideros, Jones et al. 1992; Eptesicus nilssonii, Rydell 1993), forearm length and call variables did not correlate in my data (except $L$. borealis, see Results). Call variations could be caused by genetic variance (e.g. morphometric differences between sexes), by diversity between populations and/or by traditional learning.

In L. cinereus, Barclay (1986) found longer call intervals and call durations and lower frequencies than I did, perhaps indicating a longer operational range for echolocation. L. borealis emits shorter calls of higher frequencies and bandwidths in shorter intervals when foraging at smaller sites (Main Gate; Table 5). Dependence of echolocation call design on foraging distance to obstacles have been reported from other species (e.g. Pipistrellus pipistrellus, Pye 1978; Eptesicus nilssoni, Miller and Degn 1981; Rydell 1990, 1993; Rhinopoma hardwickei, Habersetzer 1981; Plecotus phyllotis, Simmons and O'Farrell 1977; Tadarida mexicana; T. macrotis, Simmons et al. 1978; Pipistrellus kuhli, Schnitzler et al. 1987; Nyctalus noctula, Zbinden 1989; several Pipistrellus species, Kalko and Schnitzler 1993). Theory predicts long low-frequency narrowband echolocation calls for long range target detection (Simmons and Stein 1980). Long signals of moderate bandwidth can improve target detection, possibly by neural integration over the signal duration which increases the signal-to-internal-noise ratio (Simmons et al. 1977). Multiple harmonics, even in long narrowband calls used in long range detection (e.g. Fig. 3E, $\mathrm{J}, \mathrm{K}$ ), suggest that vespertilionid bats can adapt their echolocation calls to environmental constraints, but have limited control over the harmonic composition of their vocalizations.

\section{Effects of variability}

The alternating call patterns of $L$. borealis and $L$. cinereus foraging $>10 \mathrm{~m}$ above ground appears to be under the bat's direct control. Similar patterns have been described for several other vespertilionids including Nyctalus leisleri, N. noctula, Pipistrellus kuhli, Barbastella barbastellus and Chalinolobus variegatus (Watson 1970; Ahlén 1981; Obrist et al. 1989), and for emballonurids (Pye 1973; Barclay 1983). Calls of alternating frequency could separate echoes from the ground and targets ahead (Pye 1973) and could improve detection of targets with poor reflective properties at specific spectral bands. Alternating orientation to the ground and for prey ahead could produce a bimodal interval distribution, if prey and ground are at different distances. Immediately after a feeding buzz, E. fuscusproduced long broad-band calls alternating with fainter, narrow-band calls of shorter duration. Scanning head movements and vocalizations in different directions to reorient after a complex capture maneuver (Barclay 1986) could explain these amplitude patterns and their spectral and temporal effects on the analysis.

Bats dramatically change their call patterns when attacking flying insects, and temporally adjust the typical stages (search, approach, feeding buzz; Griffin et al. $1960)$ to the situational needs (personal observation). Situational flexibility and the fine differences in call structures in response to different distances from solid obstacles indicate that bats actively choose call variables to optimize information gathering. Assuming uniform neural patterns underlying the choice of signal variables in at least the same species establishes a bridge between echolocation and communication. Any eavesdropper should be able to predict the behavioral situation in which a conspecifics vocalizations are emitted. This has been demonstrated in the field by Balcombe and Fenton (1988) using playback experiments.

Using MANOVA, individual comparisons and discriminant function analysis revealed individual differences in echolocation call characteristics in all four species, confirming the hypothesis, that individuals have characteristic call designs (Brigham et al. 1989; Masters et al. 1990; Rydell 1993). In general, individual lasiurine bats foraging in the same area (without conspecifics), differ more in echolocation call design than individuals foraging at different sites (Fig. 4). This lends further credence to the hypothesis that signal variability improves individual echo recognition. The individual differences can affect recognition of one's own signals and serve in social communication if the animals occasionally encounter another bat in the foraging area.

\section{The problem of echo recognition}

Is echo recognition a problem in everyday foraging of vespertilionid bats? How likely is a bat to encounter a conspecific and register its echolocation calls? Taking into consideration the density of hunting bats (during recordings up to six in Pinery Provincial Park, several tens at the Okanagan Falls location), the average echolocation range (judged to reach $5-15 \mathrm{~m}$ in a cone of $30^{\circ}$ ) and flight speed (timed by hand, $5 \mathrm{~m} / \mathrm{s}$ ), 0-20 bat-bat encounters per hour is a conservative estimate. This assumes even exploration of space and does not consider identical regular hunting loops of several 
bats, which could drastically increase the number of encounters.

What measures decrease the susceptibility of the sonar system of bats to jamming by conspecifics? Intraspecific chases are behavioural interactions ( $E u$. maculatum, Leonard and Fenton 1983, 1984) that could eliminate the chance of interferences by avoiding batbat encounters. Directionality of sound emission (Schnitzler and Grinnell 1977) and hearing (Grinnell and Schnitzler 1977), especially when tuned to the spectral range of the vocalization (Obrist et al. 1993) increase the signal-to-noise ratio of the sonar system in frontal directions, decreasing the jamming potential of other bats' calls.

If the changes in call characteristics induced by the presence of other bats is used to improve the recognition of calls, shifts in call variables should occur upwards and downwards, not changing the variable mean. Correspondingly the discriminant function analysis does not support the jamming avoidance hypothesis as the resubstitution scores for bats flying together do not increase (Table 4B). However, when variables shift in both directions, the variability increases. My data illustrate this: the lasiurines and E. fuscus change only slightly the mean of their call variables (mainly by increasing frequency and decreasing call duration) but drastically increase the variability (CV) of the call intervals (Table 2). Spectral increase and temporal decrease (call duration and interval) point towards a switch to shorter echolocation range. Pipistrelle bats increase main frequency and bandwidth but decrease duration and interval of their calls when foraging close to clutter (Kalko and Schnitzler 1993). $L$. borealis shows identical adaptations of calls when foraging at smaller sites. In the context of conspecifics as source of clutter, this change made sense only for a bat following another, not the leading one. Additionally, in my recordings the interval increased and the changes were independent of relative position of the two bats. The changes observed can therefore be distinguished from a pure adjustment to clutter and interpreted as a jamming avoidance response (JAR). The bats do not use exclusive frequency bands as seen in the JAR of electric fish (Bullock et al. 1972; McGregor and Westby 1992) or assumed in Rhinopoma hardwickei (Habersetzter 1981). They rather appear to use distinct sonagram shapes and/or separate calls temporally by vocalizing asynchronously with conspecifics, thereby also addressing the problem of masking (Kalko and Schnitzler 1993). The importance of vocalization timing was underlined in Noctilio albiventris with the demonstration of a gating mechanism, which opens a timing window for echo processing (Roverud and Grinnell 1985). Temporally patterned calling combined with a temporal analysis window could effectively eliminate interferences. The hypothesis of asynchronous calling should be testable using radiotransmitters whose signal emissions are triggered by the vocalizations of the tagged bat.

Bats surely have temporal and spectral auditory resolution capabilities far better than the analysis applied here (e.g. Simmons et al. 1989; Schmidt 1988). The variables statistically analysed only partially describe the full echolocation calls, for I have neglected features such as shape of envelope or sonagram. Two individuals' calls with different sonagram shapes could have an identical set of the five measured variables and would not be distinguished in my analysis. Structural properties of a target (e.g. roughness, movement) and differential energy absorption in air (Lawrence and Simmons 1982) affect the analysed signal characteristics (e.g. peaks and lows in the power spectrum), but the sonagram shape would remain unaffected. Sonagrams of E. fuscus gave the impression of high shape variability. Different sonagram shapes as illustrated by the two calls in Fig. $2 \mathrm{~K}$ will evoke different responses in a detector and therefore act as individual signal attributes.

If bats' auditory systems function like an optimum receiver (Beuter 1980), signal variables such as sweep rate and bandwidth drastically influence the crosscorrelation function between signal and echo (J.A. Simmons, personal communication). I illustrate this with a simulated echolocation call (Fig. 7): two signals of identical envelope, comparable power spectrum but differing sonagram shape can produce very similar temporal resolutions (autocorrelation) and be clearly distinguishable from each other. This is illustrated by a cross-correlation, which is temporally smeared compared to both autocorrelations. Therefore, in the light of possible individual signal markers, a quantitative description of sonagram shapes should be included in future research on individual bat call characteristics.

Finally, in situations where time and frequency are confined to very narrow ranges (e.g. during a feeding buzz), intensity changes are another way to "personalize" signals. In lasiurines, catching success in first attacks is limited to about $40 \%$ (Hickey and Fenton 1990). In $60 \%$ of all audible buzzes, the target will still be available, making buzzes very attractive for $L$. borealis and $L$. cinereus. Resulting inter-specific interactions were occasionally recorded in Pinery Provincial Park. Several lasiurines tried in long trials $(>5 \mathrm{~s})$ to concurrently intercept a single moth; then, after a couple of failed attacks, an individual $L$. cinereus drastically increased the intensity of its echolocation signals.

The amount of variability I found illustrates the need to consider this topic in future studies using identification of bats by their calls for assessment of distribution or habitat use. Work involving identification of species by their calls should be executed only after estimating variation in the species under investigation. This usually means capturing the species and releasing marked individuals in the field to 


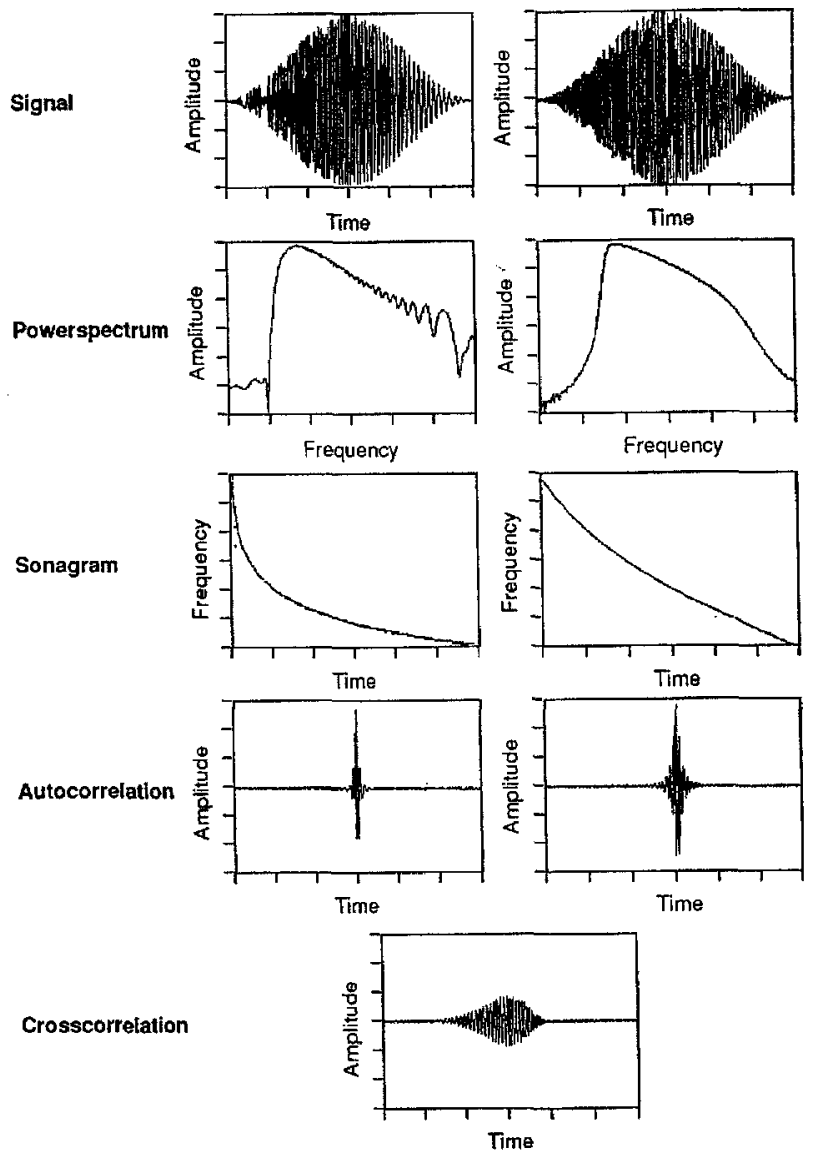

Fig. 7 Crosscorrelation. Comparison of two simulated echolocation signals which are identical in envelope and similar in power spectrum but differ in sonagram shape. Comparable autocorrelation functions are achieved with both signals, but the crosscorrelation is clearly blurred in time

assess variation in echolocation (Fenton and Bell 1981). Flexibility in echolocation should allow bats to hunt more efficiently as some signal designs are theoretically superior to others for specific tasks. A flexible species should have access to a wider variety of environments for foraging (Fenton 1990). Differing variability between species could reflect different foraging flexibility and thus their susceptibility to long term changes in their main foraging habitat.

Acknowledgments I am grateful to Dr. G. Neuweiler and Dr. M.B. Fenton for their advice during the study and for their comments on the manuscript. My special thanks are due to Christa ObristBösch for her tireless assistance in the field. R.M. Brigham and M.B.C. Hickey helped me trap bats. L. Acharya, R.M. Brigham, J.E. Cebek, M.B.C. Hickey, W. Metzner and A.D. Pinheiro made valuable suggestions on this and earlier versions of the manuscript. P. Ng clarified several statistical points and two anonymous referees contributed considerably to an improved manuscript. The administrations of Okanagan Falls Provincial Parks and Pinery Provincial Park kindly allowed access to sites. This research was supported by SFB 204 (Gehör) München, the Deutsche Akademische Austauschdienst (DAAD), Roche Research Foundation Basel, Swiss National Foundation for the Promotion of Science, and an operating grant from Natural Science and Engineering Research Council (Canada) to M.B. Fenton.

\section{References}

Ahlén I (1981) Identification of Scandinavian bats by their sounds (Department of wildlife Ecology Report 6). Swedish University of Agricultural Sciences, Uppsala

Balcombe J, Fenton MB (1988) Eavesdropping by bats: the influence of echolocation call design and foraging strategies. Ethology 79:158-166

Barclay RMR (1983) Echolocation calls of emballonurid bats from Panama. J Comp Physiol 151:515-520

Barclay RMR (1986) The echolocation calls of hoary (Lasiurus cinereus) and silver-haired (Lasionycteris noctivagans) bats as adaptations for long- versus short-range foraging strategies and the consequences for prey selection. Can J Zool 64:2700-2705

Beer CG (1970) Individual recognition of voice in the social behavior of birds. In: Lehrman DS, Hinde RA, Shaw E (eds) Advances in the study of behavior, vol 3 Academic Press, New York, pp $27-74$

Belwood JJ, Fullard JH (1984) Echolocation and foraging behavior in the Hawaiian hoary bat, Lasiurus cinereus semotus. Can J Zool 62:2113-2120

Beuter KJ (1980) A new concept of echo evaluation in the auditory system of bats. In: Busnel RG, Fish JF (eds) Animal sonar systems. Plenum, New York, pp 747-761

Brigham RM, Cebek JE, Hickey MBC (1989) Intraspecific variation in the echolocation calls of two species of insectivorous bats. J Mammal 70:426-428

Brown PE (1976) Vocal communication in the pallid bat, Antrozous pallidus. Z Tierpsychol 41:34-54

Brown PE, Brown TW, Grinnell AD (1983) Echolocation, development, and vocal communication in the lesser bulldog bat, Noctilio albiventris. Behav Ecol Sociobiol 13:287-298

Bullock TH, Hamstra RH, Scheich H (1972) The jamming avoidance response of high-frequency electric fish, I and II. J Comp Physiol 77:1-48

Cheney DL, Seyfarth RM (1980) Vocal recognition in free-ranging vervet monkeys. Anim Behav 28:362-367

Day RW, Quinn GP (1989) Comparison of treatments after an analysis of variance in ecology. Ecol Monogr 59:433-463

Fenton MB (1984) Echolocation: implications for ecology and evolution of bats. Q Rev Biol 59:33-53

Fenton MB (1985) Communication in the Chiroptera. Indiana University Press, Bloomington

Fenton MB (1990) The foraging behaviour and ecology of animaleating bats. Can J Zool 68:411-422

Fenton MB, Bell GP (1981) Recognition of species of insectivorous bats by their echolocation calls. J Mammal 62:233-243

Gelfand DL, McCracken GF (1986) Individual variation in the isolation calls of Mexican free-tailed bat pups (Tadarida brasiliensis mexicana). Anim Behav 34:1078-1086

Gould E (1971) Studies of maternal-infant communication and development of vocalizations in the bats Myotis and Eptesicus. Commun Behav Biol 5:263-313

Griffin DR (1958) Listening in the dark. Yale University Press, New Haven, Connecticut

Griffin DR, Webster FA, Michael CR (1960) The echolocation of flying insects by bats. Anim Behav 8:141-154

Grinnell AD, Schnitzler HU (1977) Directional sensitivity of echolocation in the horseshoe bat, Rhinolophus ferrumequinum. II. Behavioral directionality of hearing. J Comp Physiol $116: 63-76$

Habersetzer J (1981) Adaptive echolocation sounds in the bat Rhinopoma hardwickei. J Comp Physiol 144:559-566

Hickey MBC, Fenton MB (1990) Foraging by red bats (Lasiurus borealis): do intraspecific chases mean territoriality? Can J Zool $68: 2477-2482$

Jones G, Hughes PM, Rayner JMV (1991) The development of vocalizations in Pipistrellus pipistrellus (Chiroptera: Vesperti- 
lionidae) during post-natal growth and the maintenance of individual vocal signatures. $J$ Zool Lond 225:71-84

Jones G, Gordon T, Nightingale J (1992) Sex and age differences in the echolocation calls of the lesser horseshoe bat, Rhinolophus hipposideros. Mammalia 56:189-193

Kalko EKV, Schnitzler H-U (1993) Plasticity in echolocation signals of European pipistrelle bats in search flight: implications for habitat use and prey detection. Behav Ecol Sociobiol 33:415-428

Kolb VA (1977) Wie erkennen sich Mutter und Junges des Mausohrs, Myotis myotis, bei der Rückkehr vom Jagdflug wieder? Z Tierpsychol 44:423-431

Lawrence BD, Simmons JA (1982) Measurements of atmospheric attenuation at ultrasonic frequencies and the significance for echolocating bats. J Acoust Soc Am 71:585-590

Leonard ML, Fenton MB (1983) Habitat use by the spotted bats (Euderma maculatum, Chiroptera: Vespertilionidae): roosting and foraging behaviour. Can J Zool 61:1487-1491

Leonard ML, Fenton MB (1984) Echolocation calls of Euderma maculatum (Vespertilionidae): use in Orientation and communication. J Mammal 65:122-126

Masters WM, Jacobs SC, Simmons JA (1990) The structure of echolocation sounds used by the big brown bat, Eptesicus fuscus: some consequences for echo processing. J Acoust Soc Am $89: 1402-1413$

McGregor PK, Westby GWM (1992) Discrimination of individually characteristic electric organ discharges by a weakly electric fish. Anim Behav 43:977-986

Miller LA, Degn HL (1981) The acoustic behavior of four species of vespertilionid bats studied in the field. J Comp Physiol 142:67-74

Möhres FP (1953) Jugendentwicklung des Orientierungsverhaltens bei Fledermäusen. Naturwissenschaften 10:298-299

Möhres FP (1967) Communicative characters of sonar signals in bats. In: Busnel RG (ed) Animal sonar systems II, Laboratoire de Physiologie acoustique, Jouy-en-Josas, pp 939-945

Neuweiler G, Metzner W, Heilmann U, Rübsamen R, Eckrich M, Costa HH (1987) Foraging behavior and echolocation in the rufous horseshoe bat (Rhinolophus rouxi) of Sri Lanka. Behav Ecol Sociobiol 20:53-67

Obrist M (1988) Individually recognizable freeflying bats: a new method to record and analyze their echolocation calls. Myotis $26: 87-95$

Obrist M, Aldridge HDJN, Fenton MB (1989) Roosting and echolocation behavior of the African bat, Chalinolobus variegatus. J Mammal 70(4):828-833

Obrist MK, Fenton MB, Eger JE, Schlegel PA (1993) What ears do for bats: a comparative study of pinna sound pressure transformation in Chiroptera. J Exp Biol 180:119-152

Pye JD (1972) Bimodal distribution of constant frequencies in some hipposiderid bats (Mammalia: Hipposideridae). J Zool Lond $166: 323-335$

Pye JD (1973) Echolocation by constant frequency bats. Period Biol $75: 21-26$

Pye JD (1978) Some preliminary observations on flexible echolocation systems. Jn: Olembo RJ, Castelino JB, Mutere FA (eds) Proceedings of the Fourth International Bat Research Conference. Kenya literature bureau, Nairobi, pp 127-136
Roverud RC, Grinell AD (1985) Echolocation sound features processed to provide distance information in the CF/FM bat, Noctilio albiventris: evidence for a gated time window utilizing both CF and FM components. J Comp Physiol A 156:457-469

Rydell J (1990) Behavioral variation in echolocation pulses of the northern bat, Eptesicus nilssoni. Ethology 85:103-113

Rydell J (1993) Variation in the sonar of an aerial-hawking bat (Eptesicus nilssonii). Ethology 93:275-284

Scherrer JA, Wilkinson GS (1993) Evening bat isolation calls provide evidence for heritable signatures. Anim Behav 46:847-860

Schmidt S (1988) Evidence for a spectral basis of texture perception in bat sonar. Nature 331:617-619

Schnitzler H-U, Grinnell AD (1977) Directional sensitivity of echolocation in the horseshoe bat, Rhinolophus ferrumequinum. I. Directionality of sound emission. J Comp Physiol 116:51-61

Schnitzler H-U, Kalko E, Miller E, Surlykke A (1987) The echolocation and hunting behavior of the bat, Pipistrellus kuhli. J Comp Physiol A 161:267-274

Schumm A, Krull D, Neuweiler G (1991) Echolocation in the notcheared bat, Myotis emarginatus. Behav Ecol Sociobiol 28:255-261

Sieber OJ (1986) Acoustic recognition between mother and cubs in racoons (Procyon lotor). Behavior 96:130-163

Simmons JA, O'Farrell MJ (1977) Echolocation in the long-eared bat, Plecotus phyllotis. J Comp Physiol 122:201-214

Simmons JA, Stein RA (1980) Acoustic imaging in bat sonar: echolocation signals and the evolution of echolocation. J Comp Physiol 135:61-84

Simmons JA, Altes RA, Beuter KJ, Bullock TH, Capranica RR, Goldstein JL, Griffin DR, Konishi M, Neff WD, Neuweiler G, Schnitzler HU, Schuller G, Sovijarvi ARA, Suga N (1977) Localization and identification of acoustic signals, with reference to echolocation. In: Bullock TH (ed), Recognition of complex acoustic signals. Aberkon, Berlin, pp 239-277

Simmons JA, Lavender WA, Lavender BA, Childs JE, Hulebak K, Rigden MR, Sherman J, Woolman B, O'Farrell MJO (1978) Echolocation by free-tailed bats (Tadarida). J Comp Physiol 125:291-299

Simmons JA, Freedman EG, Stevenson SB, Chen L, Wohlgenant TJ (1989) Clutter interference and the integration time of echoes in the echolocating bat, Eptesicus fuscus. J Acoust Soc Am $86: 1318-1332$

Suthers RA, Hector DH (1988) Individual variation in vocal tract resonance may assist oilbirds in recognizing echoes of their own sonar clicks. In: Nachtigall, PE, Moore PWB (eds) Animal sonar. Plenum, New York, pp 87-91

Thomas DW, Bell GP, Fenton MB (1987) Variation in echolocation call frequencies recorded from north american vespertilionid bats: a cautionary note. J Mammal 68:842-84

Watson A (1970) Electronic aids to the identification of bats in flight and their study under natural conditions. Proceedings of the second International Bat Research Conference. Bijdr Dierk 40:99-102

Zbinden K (1989) Field observation on the flexibility of the acoustic behavior of the european bat Nyctalus noctula (Schreber, 1774). Rev Suisse Zool 96:335-343

Communicated by G.M. Klump 